\title{
Time of vaccination influences development of adhesions, growth and spinal deformities in Atlantic salmon Salmo salar
}

\author{
Arne Berg ${ }^{1, *}$, Odd Magne Rødseth ${ }^{2}$, Arild Tangerås ${ }^{2}$, Tom Hansen ${ }^{1}$ \\ ${ }^{1}$ Institute of Marine Research, 5984 Matredal, Norway \\ ${ }^{2}$ Intervet Norbio AS, Thormøhlensgt 55, 5008 Bergen, Norway
}

\begin{abstract}
In August 1998, 3000 Atlantic salmon Salmo salar L. parr were divided into 7 groups with 2 replicates. Every 6 wk until March of the following year 1 group was vaccinated. One group was held as an unvaccinated control. The fish were transferred to seawater in May 1999, and slaughtered in February 2000. Temperature, fish size and photoperiod at vaccination, and the time between vaccination and sea transfer thus varied among the groups. In all vaccinated groups, growth was reduced for 1 to 2 mo following vaccination. Intra-abdominal lesions developed faster, and stabilised at a higher level in the groups vaccinated early at the highest temperature and the smallest fish size. Growth in seawater was influenced by the time of vaccination. At the end of the experiment, the group vaccinated last (MAR) was the heaviest of the vaccinated groups $(4.0 \mathrm{~kg})$, and the group vaccinated first, i.e. in August (AUG) was smallest $(3.2 \mathrm{~kg}$ ). Growth rate in seawater differed only in the summer when specific growth rate was above 1.45 in all groups. There was a correlation between adhesion, condition factor and number of weeks from vaccination to sea transfer. The AUG group had the highest condition factor, with a top level of 1.64 in autumn, and this group also displayed the highest incidence of deformed vertebra. The experiment shows that side effects of vaccination can be significantly reduced when planning the vaccination strategy, by taking environmental factors and fish biology into consideration.
\end{abstract}

KEY WORDS: Vaccination · Side effects $\cdot$ Intra-abdominal lesions $\cdot$ Vertebral column $\cdot$ Temperature Fish size

Resale or republication not permitted without written consent of the publisher

\section{INTRODUCTION}

Furunculosis caused by Aeromonas salmonicida subsp. salmonicida was introduced to the Norwegian salmon industry with a shipment of live fish from Scotland in June 1985 (Egidius 1987), and caused considerable losses in salmon farms during the late 1980s (Midtlyng 1996). In the early 1990s the work of Krantz et al. (1964) describing the superior performance and feasibility of oil-adjuvanted furunculosis vaccines was rediscovered and this technique was subsequently adopted by the industry (Midtlyng 1996, 1998). The use of oil-based adjuvant systems has proved to induce long-lasting protective immunity against furunculosis (Midtlyng et al. 1996b), and largely reduces the risk of disease in fish farming (Midtlyng 1998). Indeed, the disease literally disappeared after 1993 as a result of these vaccines (Lillehaug et al. 2003).

In some cases, the use of oil-adjuvanted vaccines has led to considerable side effects (Poppe \& Breck 1997, Midtlyng 1998), of which the most frequently reported are injection site lesions (Midtlyng et al. 1996b, Lund et al. 1997), adhesions between internal organs (Midtlyng 1996, Midtlyng et al. 1996a), reduced appetite and growth (Midtlyng et al. 1996b, Sørum \& Damsgård 2004) and malfunction of the reproductive organs. In the worst cases, a difference in weight can still be seen $1 \mathrm{yr}$ after vaccination (Midtlyng 1998, Midtlyng \& Lillehaug 1998), which in some cases may lead to downgrading at slaughter (Midtlyng 1996, 1997, Poppe \& Breck 1997). 
Poppe \& Breck (1997) point out that the same vaccine results in dramatically different levels of side effects, both between farms and within the same populations, and Midtlyng (1996) called for further studies to identify the causative factors and means of reducing these side effects.

The production period of an S1 salmon smolt is approximately 18 mo from fertilisation in November/ December until seawater transfer in April/May. In practical fish farming it is possible to vaccinate these fish from a size of 20 to $30 \mathrm{~g}$ and until $4 \mathrm{wk}$ before transfer to seawater. The present study aimed to compare the potential short- and long-term effects on growth and the side effects of a single intraperitoneal injection administered at different times of the year during S1 salmon smolt production.

\section{MATERIALS AND METHODS}

Fish stock and rearing conditions in fresh water. Before the start of the experiment, Atlantic salmon Salmo salar parr of the Aqua Gen strain had been reared under continuous light and an average water temperature of $12 \pm 2^{\circ} \mathrm{C}$. On 21 August 1998, 3068 fish were randomly distributed into 14 square covered green indoor tanks $(1.5 \times 1.5 \times 0.7 \mathrm{~m})$ at the Institute of Marine Research, Matredal, Norway $\left(61^{\circ} \mathrm{N}\right)$. The fish were reared under simulated natural photoperiod (SNP) supplied by $2 \times 36 \mathrm{~W}$ fluorescent daylight tubes. Fresh water, buffered with $1 \%$ filtered seawater, was adjusted to maintain the oxygen content in the outlet water above $8 \mathrm{mg} \mathrm{l}^{-1}$. The water temperature during the experiment is shown in Fig. 1. The fish were fed a commercial diet (Skretting) in excess during the daylight hours of the SNP.

Experimental design. Every 6 wk from 26 August 1998 to 23 March 1999, the fish in 2 tanks (replicates) were vaccinated intraperitoneally (i.p.) with $0.2 \mathrm{ml}$ of the multivalent oil-adjuvanted vaccine Norvax $^{\circledR}$ Protect IPN Vet (the groups were designated AUG, OCT, NOV, DEC, FEB, MAR according to the month in which they were vaccinated; see also Tables 1 \& 2 and Fig. 1). Two tanks were held as unvaccinated controls (CON). All the fish were starved for $1 \mathrm{~d}$ prior to vaccination and sampling. One OCT replicate was excluded from the study because the fish in this tank were accidentally injected with only $0.1 \mathrm{ml}$ vaccine.

On 10 May 1999 the remaining fish $(\mathrm{n}=2306)$ were fin-clipped according to group. On 13 May 1999 these fish were transferred to a single sea cage $(12 \times 12 \times$ $12 \mathrm{~m})$. Commercial feed was distributed in excess, during 2 periods of $2 \mathrm{~h}$ (morning and afternoon) until the end of the experiment on 2 March 2000.

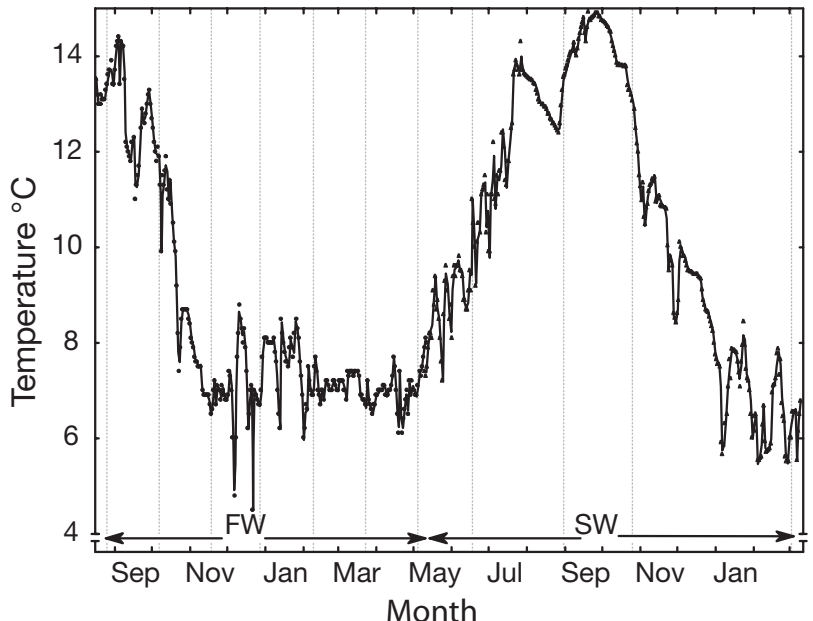

Fig. 1. Water temperature in freshwater (FW) and seawater (SW) from 26 August 1998 to 2 March 2000. Vertical dotted lines indicate dates at which vaccination and/or sampling took place

The experimental design meant that the different groups were vaccinated at different fish size, daylength and temperature. The time from vaccination to smoltification and seawater transfer varied accordingly. Because the amount of vaccine injected was constant, the dose $\mathrm{kg}$ fish $^{-1}$ decreased as fish grew $\left(4.7 \mathrm{ml} \mathrm{kg}^{-1}\right.$ in the AUG group to $1.1 \mathrm{ml} \mathrm{kg}^{-1}$ in the MAR group).

Data sampling. Randomised sampling of individual weight, length, evaluation of side-effects and blood collection was carried out as shown in Table 1. Fish sampled for autopsy and/or blood samples were stunned with a sharp blow to the head. Fish that were only measured for length and weight were anaesthetised with Benzocaine (Norsk medisinalapotek).

Intra-abdominal lesions. The severity of intraabdominal lesions was determined visually according to Midtlyng et al. (1996b). Individual fish were given a lesion score from 0 (no adhesions) to 6 (most severe adhesions and pigmentation), where 3 or higher is classified as high lesion score.

Growth. Individual fork lengths were measured to the nearest $0.1 \mathrm{~cm}$ and live body weight to the nearest $0.1 \mathrm{~g}$ in freshwater, and to the nearest $0.5 \mathrm{~cm}$ and live body weight to the nearest $5 \mathrm{~g}$ in seawater.

Fulton's condition factor was calculated as $100 \mathrm{WL}^{-3}$, where $W$ is live body weight $(\mathrm{g})$ and $L$ is fork length $(\mathrm{cm})$ (Busacker et al. 1990). Specific growth rate (SGR,\% d ${ }^{-1}$ ) was calculated as $\left(\mathrm{e}^{\mathrm{q}}-1\right) 100$ (Houde \& Scheckter 1981), where $\mathrm{q}=\left[\ln \left(W_{2}\right)-\ln \left(W_{1}\right)\right]\left(t_{2}-t_{1}\right)^{-1}$ (Bagenal \& Tesch 1978) and $W_{2}$ and $W_{1}$ are average live body weight at times $t_{1}$ and $t_{2}$ respectively. Length growth ( $\mathrm{LG}, \mathrm{mm} \mathrm{d}^{-1}$ ) was calculated as $\left(L_{2}-L_{1}\right)\left(t_{2}-t_{1}\right)^{-1}$, where $L_{2}$ and $L_{1}$ are average fork length at times $t_{1}$ and $t_{2}$, respectively. 
Mortality during the experiment was $<5 \%$ in both freshwater and seawater, and was not related to group.

Antibody levels. Blood was sampled from the caudal vein, kept on ice, centrifuged for $15 \mathrm{~min}$ at $2300 \mathrm{rpm}$ and $4^{\circ} \mathrm{C}(1065 \times g)$, and stored at $-80^{\circ} \mathrm{C}$. For the ELISA assay the plates were coated with Aeromonas salmonicida $\left(0.1 \mathrm{ml} \mathrm{well}^{-1}\right)$, or Vibrio anguillarum $\mathrm{O} 2(0.1 \mathrm{ml}$ well $^{-1}$ ). The analyses followed the procedure described by Melingen et al. (1995) with minor modifications. The optical density (OD) was read on a Titertek SCC at $492 \mathrm{~nm}$. Values are given as LOG2 titre at OD $=1$.

Sea-water challenge test. A seawater challenge test was performed on 28 April 1999, when 8 fish from each group were transferred to stagnant aerated $35 \%$ sea-

Table 1. Salmo salar. Experimental protocol for Atlantic salmon vaccinated at different times of the year. Numbers for OCT group are in parentheses. For further data on groups see Table 2

\begin{tabular}{|c|c|c|c|c|}
\hline \multirow[t]{2}{*}{ Date } & \multirow[t]{2}{*}{ Group } & \multicolumn{3}{|c|}{ Fish sampled group $^{-1}(\mathrm{n})$} \\
\hline & & $\begin{array}{l}\text { Length and } \\
\text { weight }\end{array}$ & $\begin{array}{l}\text { Lesion } \\
\text { score }\end{array}$ & $\begin{array}{c}\text { Blood } \\
\text { samples }\end{array}$ \\
\hline \multicolumn{5}{|l|}{1998} \\
\hline 26 Aug & AUG & $140^{\mathrm{a}}$ & & 20 \\
\hline 07 Oct & OCT & $58-83(74)$ & 20 & 20 \\
\hline $18 \mathrm{Nov}$ & NOV & $120-165(71)$ & 20 & 20 \\
\hline $18 \mathrm{Dec}$ & & & 20 & 20 \\
\hline $28 \mathrm{Dec}$ & $\mathrm{DEC}$ & & & \\
\hline \multicolumn{5}{|l|}{1999} \\
\hline 14 Jan & & $143-156(80)$ & & \\
\hline 09 Feb & FEB & $114-147(76)$ & 20 & 20 \\
\hline 23 Mar & MAR & $100-203(62)$ & 20 & 20 \\
\hline 05 May & & $130-163(93)$ & 20 & 20 \\
\hline 13 May $^{\text {b }}$ & $\mathrm{CON}$ & & & \\
\hline 18 Jun & & $13-20(0)$ & $17-20(0)$ & $10(0)$ \\
\hline 31 Aug & & $31-38(20)$ & $21-22(11)$ & 10 \\
\hline 26 Oct & & $29-46(14)$ & 20-30 (11) & 10 \\
\hline \multicolumn{5}{|l|}{2000} \\
\hline $02 \mathrm{Mar}$ & & $103-130(76)$ & $103-130(76)$ & 10 \\
\hline
\end{tabular}

Table 2. Salmo salar. Groups vaccinated at different times of the year, at different water temperatures and different fish weights. Day degrees: accumulated values for the first 3 wk post-vaccination

\begin{tabular}{|lccc|}
\hline \multirow{2}{*}{ Group } & \multicolumn{3}{c|}{ Vaccination } \\
\cline { 2 - 4 } & Weight $(\mathrm{g})$ & Water temp. $\left({ }^{\circ} \mathrm{C}\right)$ & Day degrees \\
\hline AUG & 43 & 13.4 & 292 \\
OCT & 85 & 11.9 & 210 \\
NOV & 102 & 6.6 & 143 \\
DEC & 127 & 6.2 & 162 \\
FEB & 154 & 6.9 & 149 \\
MAR & 179 & 6.7 & 145 \\
CON & Unvaccinated controls \\
\hline
\end{tabular}

water. After $24 \mathrm{~h}$ the fish were stunned by a blow to the head. Blood was collected with a syringe from the caudal vessels and centrifuged for $15 \mathrm{~min}$ at $4^{\circ} \mathrm{C}$ and $2300 \mathrm{rpm}(1065 \times \mathrm{g})$. Plasma was kept at $-80^{\circ} \mathrm{C}$ until chloride levels were measured on a Radiometer CMT10 chloride titrator.

Spinal deformation. During the latter part of the study it became obvious that some of the fish had a deviant body shape, with high condition factor. To investigate this further, 65 fish were filleted and the vertebral column frozen (minimum 7 fish group ${ }^{-1}$ ) at the end of the experiment. The vertebral column was subsequently X-rayed (50 mAs, $68 \mathrm{kV}, 90 \mathrm{~cm}$ ) using portable X-ray equipment (PORTA 1030A, Nakajima), on $30 \times 40 \mathrm{~cm}$ X-ray film (Agfa Structurix daylight packing, D7 DW ETE). The radiograph was digitalized on an A3 scanner and the size of each vertebra was measured using the program ImagePro ${ }^{\circledR}$. A point was manually set on the 2 dorsal margins and the posterior ventral corner of each vertebra. The $x y$ coordinates for each point $( \pm 0.1 \mathrm{~mm})$ were used to calculate dorsal length (L) and posterior height $(\mathrm{H})$. The relation between $\mathrm{L}$ and $\mathrm{H}$, together with visual examination of the radiographs, was used to determine deformation.

Statistics. Data were analysed by Statistica ${ }^{\circledR}$ software for PC (ver. 6.0, StatSoft). Data were checked for normality by graphical presentations of frequency distribution and probability plots with normal equivalent derivates (Sokal \& Rohlf 1995), and subsequently tested for homogeneity of variance both visually and using Levene's test (Brown \& Forsythe 1974). In all statistics the individual fish was the experimental unit.

Vaccination groups were compared using ANOVA. All parallels were combined because a 2-way ANOVA showed no significant differences, with only a few random exceptions.

Fortunately, ANOVA is robust, operating well even with considerable heterogeneity of variance as long as the number of fish in each group was equal or nearly equal. Furthermore, the heterogeneity was associated with large samples and thus the main effect on the ANOVA was a lower probability of a Type I error (Zar 1996). The powerful ANOVA parametric test was used even when the assumption of heterogeneity of variance was not fully met. ANOVA was also used on the classified data of intra-abdominal lesions, and the results were similar to those obtained using a non-parametric test.

A significance level of $\mathrm{p}<0.05$ was adopted in all statistics. When the ANOVA revealed significant effects between groups, a post-hoc comparison was performed using the Newman-Keuls test. The number of deformed vertebra was compared between vaccination groups using a $\chi^{2}$-test, with Bonferroni-corrected p-level for multiple samples. Correlations were performed by Pearson product-moment correlation. 


\section{RESULTS}

\section{Intra-abdominal lesions}

All the vaccinated fish developed intra-abdominal lesions with adhesions and melanin deposits in the body cavity. The lesion score in the AUG group reached a level of $2.45 \mathrm{six}$ wk after vaccination. After this first period the increase was slower (Fig. 2a). In the other vaccinated groups the development of intraabdominal lesions was slower, and they reached lower levels.
The proportion of fish with a high lesion score (i.e. 3 or more) was greater than $60 \%$ in all samplings in the AUG group (data not shown). At the end of the experiment $81 \%$ of the fish in this group had high lesion scores (Fig. 3b). Between 40 and $45 \%$ of the OCT and NOV groups had high lesion scores, while in the other groups the corresponding figure was $17 \%$ or less.

Lesion scores in the AUG, OCT and NOV groups fell during spring and the first period in seawater (Fig. 2a). During the summer the lesion scores increased again, and in all groups the highest lesion scores were found in August or October.

Fish size at vaccination, and daydegrees during the first $3 \mathrm{wk}$ after vaccination differed from group to group. At the end of the experiment small fish displayed a higher percentage of high lesion scores $\left(r^{2}=0.9\right)$. Similarly, daydegrees during the first $3 \mathrm{wk}$ after vaccination correlated with the percentage of high lesion scores $\left(r^{2}=0.74\right)$, and there was a correlation between lesion score and number of wk between vaccination and transfer to seawater $\left(\mathrm{r}^{2}=\right.$ 0.81) (Fig. 3a).

Between 6 and 12 wk after vaccination all the vaccinated groups had developed melanin deposits on the visceral organs and/or on the parietal peritoneum. At the end of the experiment the AUG group had most and MAR least melanin of all vaccinated groups. The AUG group had most vaccine residues.

\section{Body size, growth and condition factor}

All the vaccinated groups had a reduction in growth compared to the unvaccinated control group in the period immediately after vaccination. (Fig. 4a,c). At transfer to seawater, all the vaccinated groups were thus significantly smaller than the unvaccinated control group (Fig. 4a), and there were no significant differences between the vaccinated groups. Condition factor decreased in all groups from January onwards throughout the freshwater period and into the first period in seawater.

In June, after 6 wk in seawater, no significant differences in length were
Fig. 2. Salmo salar. (a) Intra-abdominal lesion score and (b) antibody resorption against Vibrio salmonicida for groups of Atlantic salmon vaccinated at different times of the year (vaccinated in August: AUG; October: OCT; November: NOV; December: DEC; February: FEB; March: MAR), and for an unvaccinated control group (CON). Fish were scored visually on a scale of 0 (no lesions) to 6. Different letters denote significant differences between groups. Error bars indicate SE 

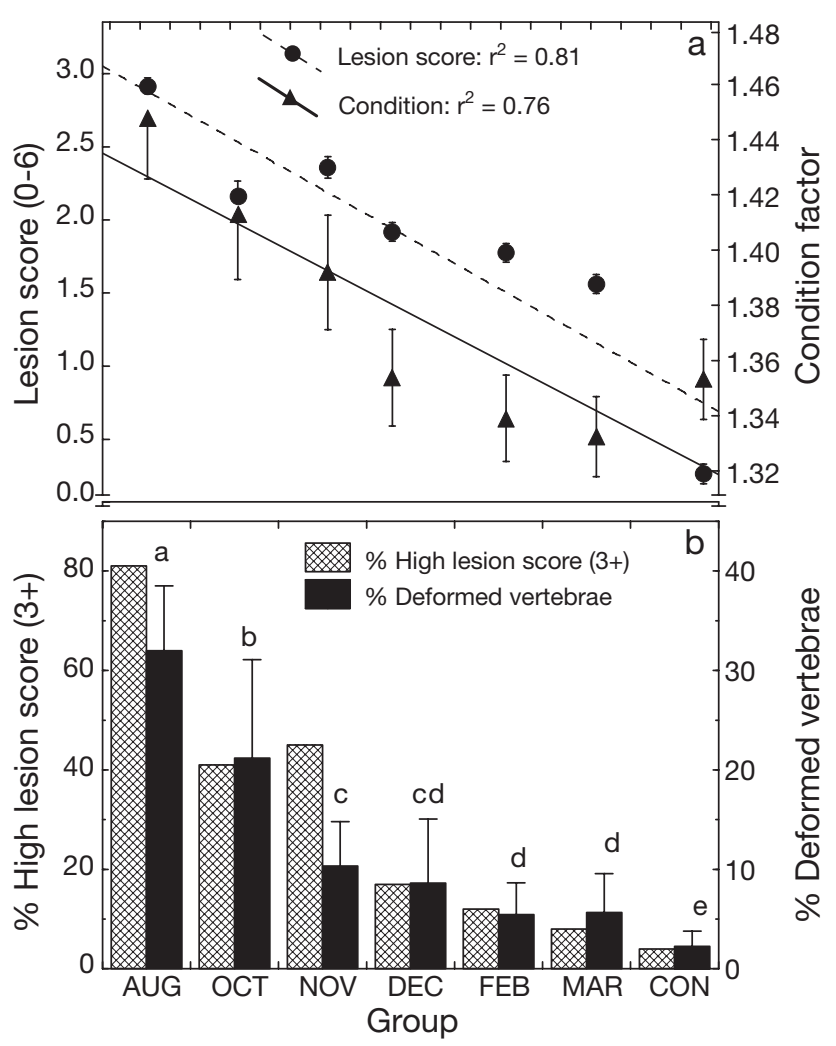

Fig. 3. Salmo salar. (a) Groups of Atlantic salmon vaccinated at different times of the year (for an explanation of groups see Fig. 2), or held unvaccinated (CON) vs. intra-abdominal lesions (triangle on left axis), and condition factor (circle on right axis), at the end of the experiment. Correlation made on week after vaccination to seawater transfer. (b) Percentage of fish with high lesion score $(3+)$ in each group and percentage deformed vertebrae in each group, at the end of the experiment. Different letters denote significant differences between groups. Error bars indicate SE

found. However, condition factor was affected, being lowest in the CON group (1.04 \pm 0.03$)$ and significantly lower in this group than in all the other groups with the exception of the NOV group.

In seawater, the biggest differences in growth were found between June and October. This coincided with the highest seawater temperatures and the period with the highest growth rates. In this period, the condition factor rose to 1.64 in the AUG group, while the CON group showed greater length growth than the other groups (Fig. 4c), being significantly longer than any of the other groups in October and at the end of the experiment (Fig. 4a). Maximum SGRs were 1.74 and 1.48 in the CON and AUG groups respectively.

At the end of the experiment the individuals in the AUG group were significantly shorter than any of the other groups and had a higher condition factor than all the groups vaccinated from December onwards. Final length correlates with week from vaccination to seawater transfer $\left(r^{2}=0.83\right)$. A similar correlation was found for condition factor $\left(r^{2}=0.76\right)$. The groups vaccinated earliest had the highest condition factor at slaughter (Fig. 3a). Mean weights $(\mathrm{kg})$ at slaughter were $4.6 \pm 0.1$ (CON), $4.0 \pm 0.1$ (MAR), $3.9 \pm 0.1$ (FEB), $4.0 \pm 0.1$ (DEC), $3.8 \pm 0.1(\mathrm{NOV}), 3.7 \pm 0.1$ (OCT), and $3.2 \pm 0.1$ (AUG).

At transfer to seawater all groups displayed normal signs of being smolt (i.e. reduced condition and more silvery). The average chloride levels after the seawater challenge test were lower than $146 \mathrm{mMol}$ in all groups.

\section{Vertebral deformations}

The proportion of deformed vertebra was $32 \%$ in the AUG group (Fig. 3b). The later the groups were vaccinated, the lower the percentages of deformed vertebra, with the lowest level $(2.3 \%)$ observed in the unvaccinated group.

The percentage of deformed vertebra correlated with the percentage of high lesion scores $\left(r^{2}=0.88\right)$, and number of day-degrees during the first $3 \mathrm{wk}$ after vaccination $\left(\mathrm{r}^{2}=0.95\right)$. There was a negative correlation between the percentage of deformed vertebrae and fish size at vaccination $\left(\mathrm{r}^{2}=0.85\right)$.

The deformations found in this experiment were platyspondyly, in which the vertebrae were compressed in the dorso-ventral direction. The typical $\mathrm{X}$ seen on radiographs of normal vertebrae became more or less diffuse and the shape of the $\mathrm{X}$ was changed to resemble II, H, )(, or other forms (Fig. 5).

The number of deformed vertebrae was lowest in Region 1, with the anterior vertebrae 1 to 8 (Fig. 6). In Region 2 (vertebrae 9 to 29) there was a rapid increase in the number of deformed vertebrae up to a maximum of $35 \%$. There was a rapid fall in the number of deformed vertebrae dorsally to the caudal constraint of the abdominal cavity. From vertebra 30, in Region 3, the number of deformed vertebrae increased again by $10-15 \%$ to $70-75 \%$ in Region 4 .

\section{Antibody levels}

All vaccinated groups displayed an increase in humoral immune response against Vibrio salmonicida after vaccination (Fig. 2b). The increase was fastest and reached the highest levels in the groups vaccinated earliest. The levels fell during the experiment, and there were small differences between the vaccinated groups after transfer to seawater, when the group vaccinated last (MAR) had a significantly lower level than all other groups except AUG. In August, MAR had a significantly higher antibody level than the other groups. The analyses of Aeromonas salmonicida showed similar trends to $V$. anguillarum (data not shown). 

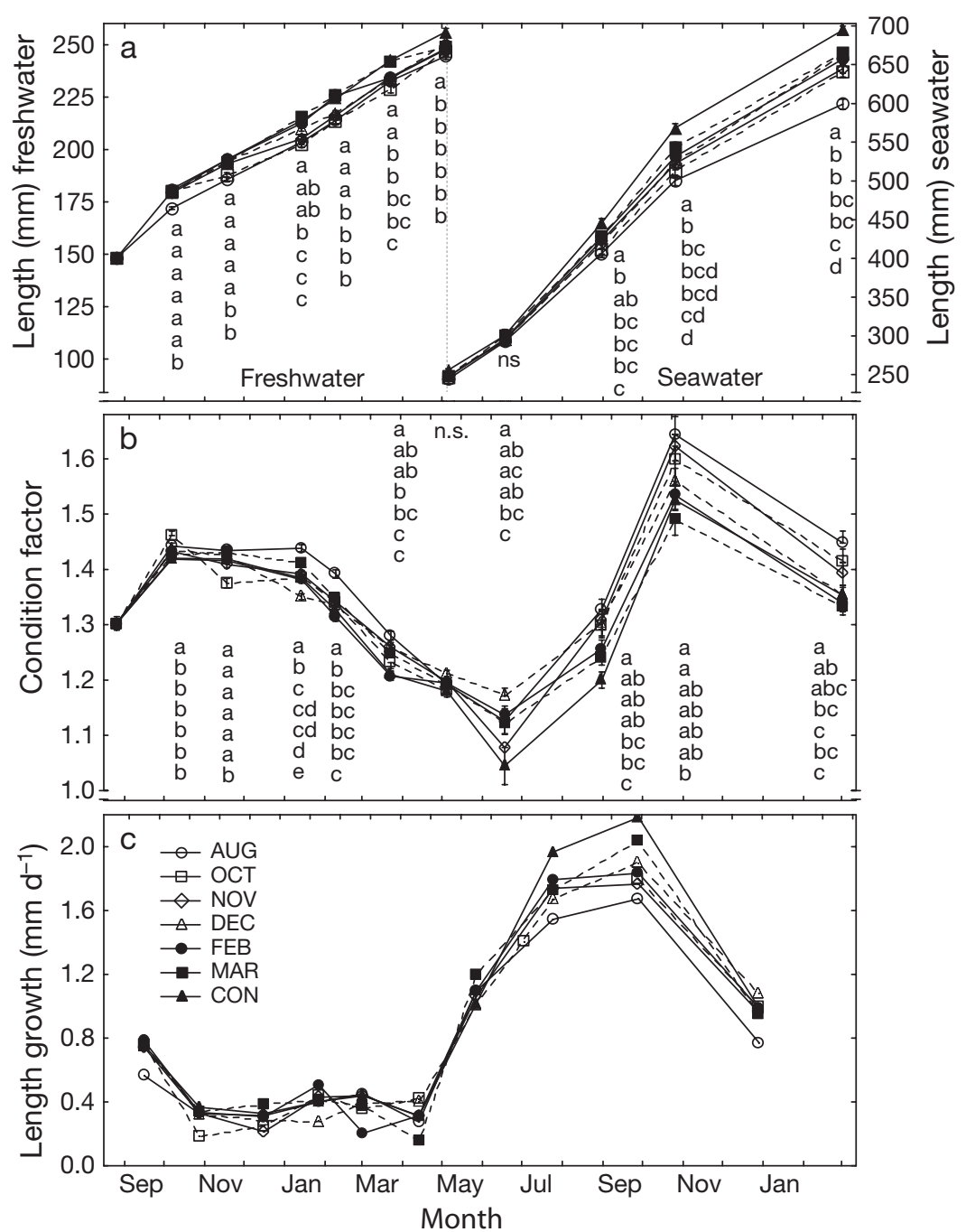

Fig. 4. Salmo salar. (a) Fork length, (b) condition factor and (c) length growth for groups of Atlantic salmon vaccinated at different times of the year, and for an unvaccinated control group (CON). For an explanation of groups see Fig. 2. In (a) values for freshwater are on the left $y$-axis, while values for seawater are on the right $y$-axis. The vertical dotted line indicates transfer to seawater. Note that length growth (c) is lowest for the group vaccinated last in each sample in freshwater. Different letters denote significant differences between groups. Error bars indicate SE

\section{DISCUSSION}

\section{Intra-abdominal lesions}

This is the first vaccination experiment in which a large number of fish have been sampled at short and regular intervals from vaccination to slaughter. This makes it possible to describe the growth and development dynamics of intra-abdominal lesions. All in all, our results confirm earlier studies in which oil-adjuvanted vaccines have been shown to induce injection site lesions (Midtlyng et al. 1996b, Poppe \& Breck 1997, Mutoloki et al. 2004) and adhesions between internal organs (Midtlyng 1996, Midtlyng et al. 1996b, Poppe \& Breck 1997), and that these lesions persist throughout the production cycle (Midtlyng 1996, 1997, Poppe \& Breck 1997). However, the same vaccine can result in dramatically different side effects both between farms and within the same population (Poppe \& Breck 1997), and the severity of lesions varies considerably between studies and samplings, suggesting that unidentified factors are influencing the development of the lesions (Midtlyng 1998). Colquhoun et al. (1998) found that injection of Pseudomonas fluorescens combined with crowding stress increased the degree of adhesion, but suggested that these parameters were not the cause of the majority of variation in lesions. Epitheliocystis, sea site (fjord vs. oceanic) and time of rearing in seawater have also been identified as risk factors in the development of abdominal lesions (Vågsholm \& Djupvik 1999).

In the present study, the groups vaccinated early, when fish were smallest and temperatures highest, developed the most severe intra-abdominal lesions. We conclude that these were the most important factors determining side effects, but factors such as photoperiod and growth rate may also have contributed to the differences.

The injected vaccine dose was constant according to aquaculture practice. The amount of vaccine injected per $\mathrm{kg}$ fish was lower in large fish, and this can explain why small fish developed more intra-abdominal lesions. The reason to vaccinate is thus to obtain protection, and it is unclear whether a reduced dose in small fish will reduce initial immune response or long-term protection.

Colquhoun et al. (1998) suggested that the severity of adhesions appears to be established fairly early after vaccination. Our data support this, as groups vaccinated within only $6 \mathrm{wk}$ of each other exhibited large differences in the severity of lesions. Furthermore, the adhesion score, which is determined in the initial period following vaccination, remained fairly stable until the fish were slaughtered. The only small deviation from this pattern was found in the AUG, OCT and NOV groups, which displayed a reduction in adhesions during the late winter and early spring in freshwater. This 


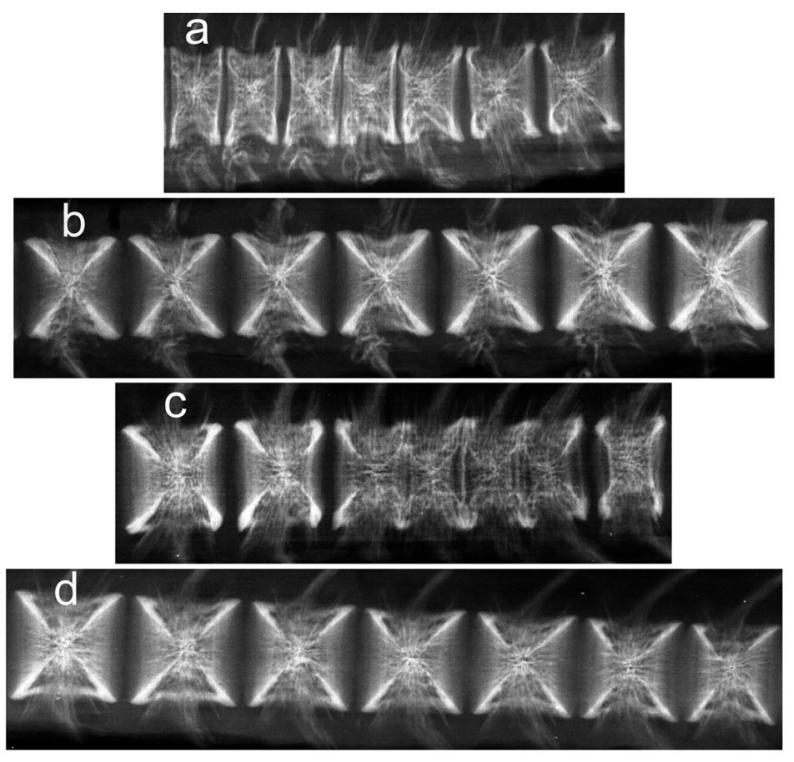

Fig. 5. Salmo salar. X-rays of deformed vertebrae with various degrees of platyspondyly from $(a, c)$ the group vaccinated in August, and $(b, d)$ normal vertebrae from the unvaccinated group. The trunkal vertebrae in $(a, b)$ are numbers 23 to 29 and the caudal vertebrae numbers 46 to 52

corresponds to a period with low temperature and reduced growth rate. After transfer to seawater both temperature and growth increased and all groups showed increased levels of adhesions during summer and autumn in the sea. Other studies have also reported an increase in intra-abdominal lesions until 6 mo (Midtlyng et al. 1996b, Mutoloki et al. 2004) or more (Hoel \& Lillehaug 1997) after vaccination. Others, e.g. Vågsholm \& Djupvik (1999), Mutoloki et al. (2004) reported a reduction in adhesions before harvest.

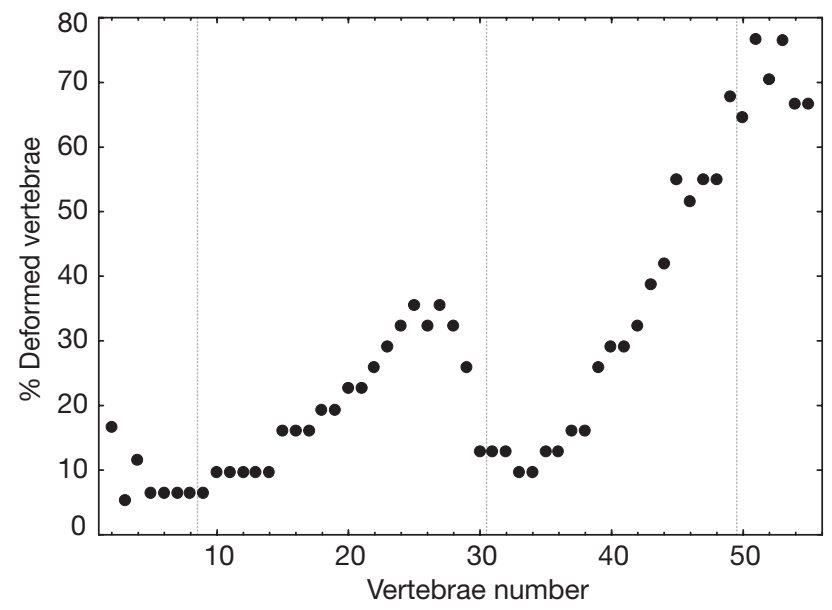

Fig. 6. Salmo salar. Percentage of deformed vertebra $(\mathrm{n}=414)$ for each vertebra number in the fishes with deformed vertebra $(\mathrm{n}=31)$. All groups are combined. Grids indicate Regions 1 to 4 (Kacem et al. 1998)

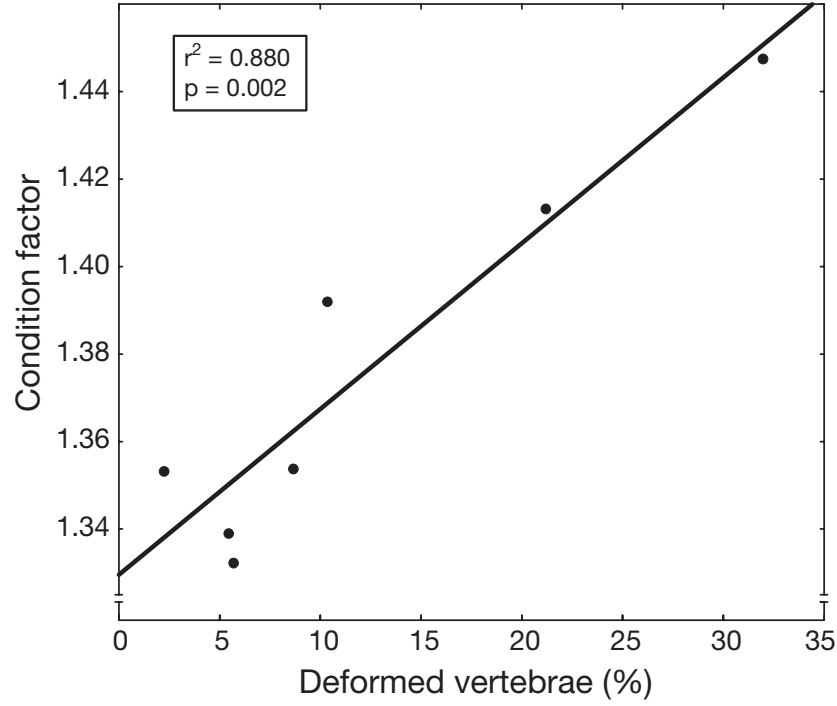

Fig. 7. Salmo salar. Correlation between percentage of deformed vertebrae in each group and condition factor at slaughter

\section{Growth and condition factor}

In accordance with earlier studies on Atlantic salmon (Midtlyng et al. 1996b, Midtlyng \& Lillehaug 1998, Sørum \& Damsgård 2004), the growth of the oil-adjuvant vaccine groups was found to be impaired in comparison with the unvaccinated controls in the first period after vaccination. Similar results have also been found in rainbow trout Oncorhynchus mykiss (Rønsholdt \& McLean 1999), Arctic charr Salvelinus alpinus (Pylkkö et al. 2000), European whitefish Coregonus lavaretus L. (Koskela et al. 2004), and spotted wolffish Anarhichas minor L. and halibut Hippoglossus hippoglossus (Ingilæ et al. 2000), but not in Atlantic cod Gadus morhua L. (Mikkelsen et al. 2004).

In the current study the initial reduction in growth was independent of time of vaccination. The vaccinated groups were on average $11 \%$ smaller than the CON group 6 wk after vaccination.

Possible factors contributing to the weight loss in the first period are loss of appetite due to handling, anaesthesia and vaccination procedures (Horne \& Ellis 1988) and side effects such as injection-site lesions and visceral adhesions (Midtlyng et al. 1996b). Hoel \& Lillehaug (1997) found differences in weight between Atlantic salmon injected with an oil-adjuvanted vaccine and saline control, indicating that the vaccine itself makes a major contribution to the reduction in growth rate. Recently, Sørum \& Damsgård (2004) found reduced feed intake and growth during the first $3 \mathrm{wk}$ after vaccination, but anaesthetisation and handling alone had no significant effect on feed intake. 
In seawater all groups displayed a typical growth pattern (e.g. Oppedal et al. 1999, Mørkøre \& Rørvik 2001, Nordgarden et al. 2003) with high and increasing growth and condition factor through the summer and up until late autumn. However, the growth and development of condition factor was highly dependent on the time of vaccination, with the lowest growth rate and highest condition factor being found in the groups vaccinated early, and the highest growth rate and lowest condition factor in the unvaccinated control. In some earlier studies lower weights compared to controls were seen $1 \mathrm{yr}$ after vaccination (Midtlyng 1998, Midtlyng \& Lillehaug 1998), or between different vaccines (Oppedal et al. in press), confirming the results of the present study. However, Hoel \& Lillehaug (1997) and Mutoloki et al. (2004) found no reduction in weight in oil-adjuvant vaccinated salmon 17 wk and 12 mo post-vaccination, and Buchmann et al. (1997) found higher weights than in controls 4 mo after vaccine administration.

The observation that the highest condition factors were found in the groups with the lowest growth rates is surprising, as condition factor normally improves with growth rate (e.g. Storebakken \& Austreng 1987). In our study, the higher than normal condition factors in the groups vaccinated early are highly correlated with the incidence of deformations in the vertebral column (Fig. 7).

\section{Antibody levels}

All groups showed the expected response in antibody levels after vaccination. There was a gradual reduction until slaughter. The groups vaccinated last did not reach the same level as those vaccinated early, probably as a result of lower temperatures, and the greater size of the fish at vaccination. At the time of transfer to sea, all groups had adequate levels of antibodies.

\section{Vertebral deformations}

In the Atlantic salmon farming industry, a number of different skeletal deformations have been reported (Kvellestad et al. 2000, Poppe et al. 2002, Silverstone \& Hammel 2002). Factors such as genetics (McKay \& Gjerde 1986, Gjerde et al. 2005), oxytetracycline administration (Toften \& Jobling 1996), diet composition (Vielma \& Lall 1998, Ørnsrud et al. 2002), and incubation temperature (Takle et al. 2005, Wargelius et al. 2005) may be involved in the development of deformed vertebrae.

Our study identifies i.p. vaccination with oil-adjuvanted vaccines as an important risk factor in the development of vertebral deformities in Atlantic salmon. Vågsholm \& Djupvik (1998) also found that smolt size and time of vaccination influenced the risk of short tails at slaughter. In the present study, most of the deformed vertebrae were in the tail region, and some in the mid-region of the fish. Toften \& Jobling (1996) found most deformities in the mid-region (vertebrae 11 to 26 ) in salmon fed oxytetracycline, while Witten et al. (2005) studied fish with compressed vertebrae all over the spinal column. In rainbow trout infected with Flavobacterium psychrophilium the deformities were randomly distributed over the spinal column (Madsen et al. 2001).

The mechanism behind the development of these vertebral deformations is still unclear. However, the similarity in the effects of vaccination time on the incidence of intra-abdominal lesions and the incidence of deformed vertebrae suggests that there could be a connection between the two, or that they are both affected by one or several common factors.

Witten et al. (2005) suggested that mechanical load produced changes in the vertebrae at a stage where the vertebrae were $5 \mathrm{~mm}$ in height. Kvellestad et al. (2000) reported major changes in the intervertebral space, including inflammatory cells, between vertebrae with platyspondyly. It is also shown that Atlantic salmon can display regional differences in vertebral growth. During smoltification, vertebrae growth is high in the caudal region. In underyearling postsmolts exposed to continuous light, growth is highest in the trunk (Fjelldal et al. 2005). This may be a sensitive period for deformations. All these findings are supported by the deformations shown in the computer tomography (CT)-scan (Fig. 8), which indi-

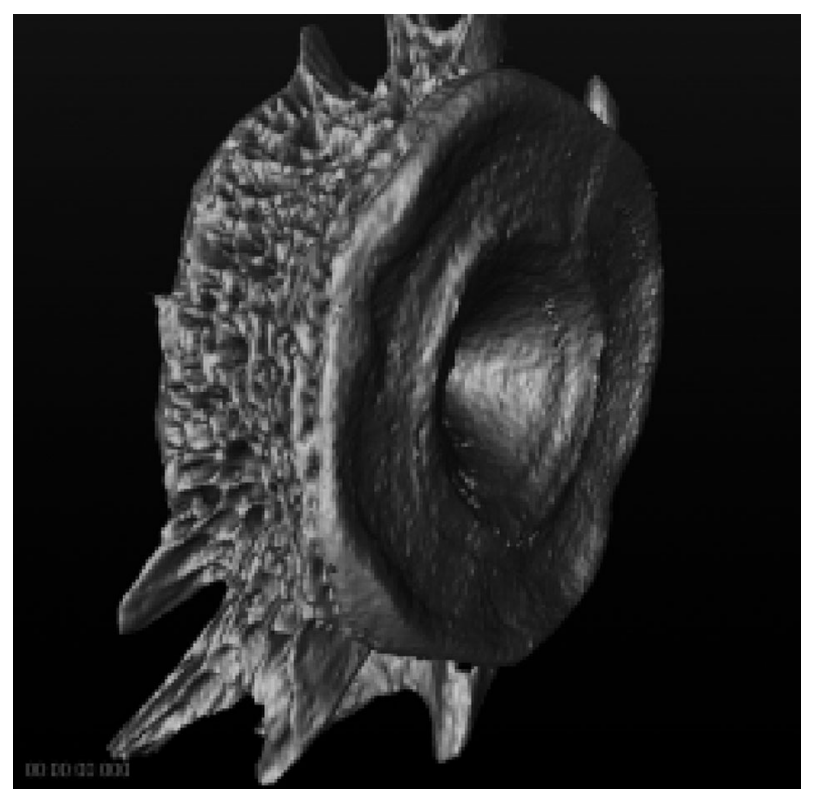

Fig. 8. Salmo salar. Micro computer tomography (CT)-scan of compressed vertebrae from the group vaccinated in August 
cates that at a particular period of growth there was a change in the direction of growth in the bone layer which forms the amphicoel, rather than a compression of a normal vertebra.

Acknowledgements. This experiment was part of the industrial project Optimal vaccination strategy, funded by Intervet Norbio AS. The authors thank I. H. Matre, A. Gullanger, C. Moen and the rest of the staff at the Institute of Marine Research, Matre for excellent technical assistance, and C. Skaar at Intervet Norbio AS for analysing the blood samples. We also thank S. Grotmol and his colleagues at the Department of Biology, University of Bergen for performing the CT-scans.

\section{LITERATURE CITED}

Bagenal TB, Tesch FW (1978) Age and growth. In: Bagenal TB (ed) Methods for assessment of fish production in fresh waters. Blackwell Scientific Publications, Oxford, p 101-136

Brown MB, Forsythe $A B$ (1974) Robust test for equality of variances. J Am Stat Assoc 69:364-367

Buchmann K, Dalsgaard I, Nielsen ME, Pedersen K, Uldal A, Garcia JA, Larsen JL (1997) Vaccination improves survival of Baltic salmon (Salmo salar) smolts in delayed release sea ranching (net-pen period). Aquaculture 156:335-348

Busacker GP, Adelman IR, Goolish EM (1990) Growth. In: Schreck CB, Moyle PB (eds) Methods for fish biology. American Fisheries Society, Bethesda, MD, p 363-387

Colquhoun DJ, Skjerve E, Poppe TT (1998) Pseudomonas fluorescens, infectious pancreatic necrosis virus and environmental stress as potential factors in the development of vaccine-related adhesions in Atlantic salmon, Salmo salar L. J Fish Dis 21:355-364

Egidius E (1987) Import of furunculosis to Norway with Atlantic salmon smolts from Scotland. International Council for the Exploration of the Sea (ICES), Mariculture Committee, CM 1987/F:8

Fjelldal PG, Nordgarden U, Berg A, Grotmol S, Totland GK, Wargelius A, Hansen T (2005) Vertebrae of the trunk and tail display different growth rates in response to photoperiod in Atlantic salmon, Salmo salar L., post-smolts. Aquaculture 250:516-524

Gjerde B, Pante MJR, Baeverfjord G (2005) Genetic variation for a vertebral deformity in Atlantic salmon (Salmo salar). Aquaculture 244:77-87

Hoel K, Lillehaug A (1997) Adjuvant activity of polar glycopeptidolipids from Mycobacterium chelonae in experimental vaccines against Aeromonas salmonicida in salmonid fish. Fish Shellfish Immunol 7:365-376

Horne MT, Ellis AE (1988) Strategies of fish vaccination. In: Ellis AE (ed) fish vaccination. Academic Press, London, p 55-66

Houde ED, Scheckter RC (1981) Growth rates, rations and cohort consumptions of marine fish larvae in relation to prey concentration. Rapp P-V Reun Cons Int Explor Mer 178:441-453

Ingilæ M, Arnesen JA, Lund V, Eggset G (2000) Vaccination of Atlantic halibut Hippoglossus hippoglossus L., and spotted wolffish Anarhichas minor L., against atypical Aeromonas salmonicida. Aquaculture 183:31-44

Kacem A, Meunier FJ, Baglinière JL (1998) A quantitative study of morphological and histological changes in the skeleton of Salmo salar during its anadromous migration. J Fish Biol 53:1096-1109

Koskela J, Rahkonen R, Pasternack M, Knuutinen H (2004) Effect of immunization with two commercial vaccines on feed intake, growth, and lysozyme activity in European whitefish (Coregonus lavaretus L.). Aquaculture 234: $41-50$

Krantz GE, Reddecliff JM, Heist CE (1964) Immune response of trout to Aeromonas salmonicida. Part 1. Development of agglutinating antibodies and protective immunity. Prog Fish Cult 26:3-10

Kvellestad A, Høie S, Thorud K, Tørud B, Lyngøy A (2000) Platyspondyly and shortness of vertebral column in farmed Atlantic salmon Salmo salar in Norway - description and interpretation of pathologic changes. Dis Aquat Org 39:97-108

Lillehaug A, Lunestad BT, Grave K (2003) Epidemiology of bacterial diseases in Norwegian aquaculture - a description based on antibiotic prescription data for the ten-year period 1991 to 2000. Dis Aquat Org 53:115-125

Lund RA, Midtlyng PJ, Hansen LP (1997) Post-vaccination intra-abdominal adhesions as a marker to identify Atlantic salmon, Salmo salar L., escaped from commercial fish farms. Aquaculture 154:27-37

Madsen I, Arnbjerg J, Dalsgaard I (2001) Radiological examination of the spinal column in farmed rainbow trout Oncorhynchus mykiss (Walbaum): experiments with Flavobacterium psychropilum and oxytetracycline. Aquac Res 32:235-241

McKay LR, Gjerde B (1986) Genetic variation for a spinal deformity in Atlantic salmon, Salmo salar. Aquaculture 52: $263-272$

Melingen OG, Nilsen F, Wergeland HI (1995) The serum antibody levels in Atlantic salmon (Salmo salar L.) after vaccination with Vibrio salmonicida at different times during the smoltification and early post-smolt period. Fish Shellfish Immunol 5:223-235

Midtlyng PJ (1996) A field study on intraperitoneal vaccination of Atlantic salmon (Salmo salar L.) against furunculosis. Fish Shellfish Immunol 6:553-565

Midtlyng PJ (1997) Vaccinated fish welfare: protection versus side-effects. In: Gudding R, Lillehaug A, Midtlyng PJ, Brown F (eds) Fish vaccinology. Dev Biol Stand 90: 371-379

Midtlyng PJ (1998) Evaluation of furunculosis vaccines in Atlantic salmon. Experimental and field studies for assessment of protection and side-effects. Dr. scient. thesis, Norwegian College of Veterinary Medicine, Oslo

Midtlyng PJ, Lillehaug A (1998) Growth of Atlantic salmon Salmo salar after intraperitoneal administration of vaccines containing adjuvants. Dis Aquat Org 32:91-97

Midtlyng PJ, Reitan LJ, Lillehaug A, Ramstad A (1996a) Protection, immune responses and side effects in Atlantic salmon (Salmo salar L.) vaccinated against furunculosis by different procedures. Fish Shellfish Immunol 6:599-613

Midtlyng PJ, Reitan LJ, Speilberg L (1996b) Experimental studies on the efficacy and side-effects of intraperitoneal vaccination of Atlantic salmon (Salmo salar L.) against furunculosis. Fish Shellfish Immunol 6:335-350

Mikkelsen H, Schøder MB, Lund V (2004) Vibriosis and atypical furunculosis vaccines; efficacy, specifity and side effects in Atlantic cod, Gadus morhua L. Aquaculture 242: 81-91

Mørkøre T, Rørvik KA (2001) Seasonal variation in growth, feed utilisation and product quality of farmed Atlantic salmon (Salmo salar L.) transferred to seawater as 0+ smolts or 1+ smolts. Aquaculture 199:145-158 
Mutoloki S, Alexandersen S, Evensen Ø (2004) Sequential study of antigen persistence and concomitant inflammatory reactions relative to side-effects and growth of Atlantic salmon (Salmo salar L.) following intraperitoneal injection with oil-adjuvanted vaccines. Fish Shellfish Immunol 16:633-644

Nordgarden U, Oppedal F, Taranger GL, Hemre GI, Hansen $\mathrm{T}$ (2003) Seasonally changing metabolism in Atlantic salmon (Salmo salar L.). I. Growth and feed conversion ratio. Aquac Nutr 9:287-293

Oppedal F, Taranger GL, Juell JE, Fosseidengen JE, Hansen $\mathrm{T}$ (1999) Growth, osmoregulation and sexual maturation of underyearling Atlantic salmon smolt Salmo salar L. exposed to different intensities of continuous light in sea cages. Aquacult Res 30:491-499

Oppedal F, Berg A, Olsen RE, Taranger GL, Hansen T (in press) Photoperiod in seawater influenced seasonal growth and chemical composition in Atlantic salmon (Salmo salar L.) underyearling smolts. Aquaculture

Ørnsrud R, Graff LE, Hoie S, Totland GK, Hemre GI (2002) Hypervitaminosis A in first-feeding fry of the Atlantic salmon (Salmo salar L.). Aquac Nutr 8:7-13

Poppe TT, Breck O (1997) Pathology of Atlantic salmon Salmo salar intraperitoneally immunized with oil-adjuvated vaccine. A case report. Dis Aquat Org 29:219-226

Poppe TT, Barnes AC, Midtlyng PJ (2002) Welfare and ethics in fish farming. Bull Eur Assoc Fish Pathol 22:148-151

Pylkkö P, Lyytikäinen T, Ritola O, Pelkonen S (2000) Vaccination influences growth of Arctic charr. Dis Aquat Org 43: $77-80$

Rønsholdt B, McClean E (1999) The effect of vaccination and vaccine components upon short-term growth and feed conversion efficiency in rainbow trout. Aquaculture 174: 213-221

Silverstone AM, Hammel L (2002) Spinal deformities in farmed Atlantic salmon. Can Vet J 43:782-784

Sokal RR, Rohlf FJ (1995) Biometry. Freeman, New York

Editorial responsibility: Carl B. Schreck, Corvallis, Oregon, USA
Sørum U, Damsgård B (2004) Effects of anaesthetization and vaccination on feed intake and growth in Atlantic salmon (Salmo salar L.). Aquaculture 232:333-341

Storebakken T, Austreng E (1987) Ration levels for salmonids II. Growth, feed intake, protein digestibility, body composition, and feed conversion in rainbow trout weighing $0.5-1.0 \mathrm{~kg}$. Aquaculture: 60:207-221

Takle H, Baeverfjord G, Lunde M, Kolstad K, Andersen $\varnothing$ (2005) The effect of heat and cold exposure on HSP70 expression and development of deformities during embryogenesis of Atlantic salmon (Salmo salar). Aquaculture 249:515-524

Toften H, Jobling M (1996) Development of spinal deformities in Atlantic salmon and Arctic charr fed diets supplemented with oxytetracycline. J Fish Biol 49: 668-677

Vågsholm I, Djupvik HO (1998) Risk factors for spinal deformities in Atlantic salmon, Salmo salar L. J Fish Dis 21: 47-53

Vågsholm I, Djupvik HO (1999) Risk factors for abdominal adhesions in Atlantic salmon, Salmo salar L. J Fish Dis 22: $53-58$

Vielma J, Lall SP (1998) Phosphorus utilization by Atlantic salmon (Salmo salar) reared in freshwater is not influenced by higher dietary calcium intake. Aquaculture 160: $117-128$

Wargelius A, Fjelldal PG, Hansen T (2005) Heat shock during early somitogenesis induces caudal vertebral column defects in Atlantic salmon (Salmo salar). Dev Genes Evol 215:350-357

Witten PE, Gil-Martens L, Hall BK, Huysseune A, Obach A (2005) Compressed vertebrae in Atlantic salmon Salmo salar: evidence for metaplastic chondrogenesis as a skeletogenic response late in ontogeny. Dis Aquat Org 64: $237-246$

Zar JH (1996) Biostatistical analysis, 3rd edn. Prentice Hall, Upper Saddle River, NJ

Submitted: September 2, 2005; Accepted: December 14, 2005 Proofs received from author(s): March 12, 2006 